\title{
Response of Small Mammals to Livestock Grazing in Southcentral Idaho
}

\author{
MARK K. JOHNSON
}

\begin{abstract}
The effects of livestock grazing on populations of wildlife have been addressed in two recent studies on the INEL Site. However, studies were performed by measuring indices of abundance among areas where different practices had occurred prior to initiation of study. There is no proof that differences detected among the areas actually resulted from the land use practices. Studies should be conducted with replication and strict controls before correlated data can be accepted as indicators of cause and effect relationships. The large variation in the occurrence and densities of small mammals among areas with the same or similar uses suggests the need for further studies to resolve conflicting conclusions.
\end{abstract}

Recently four areas were studied on the Idaho National Engineering Laboratory (INEL) Site to compare the effects of sheep grazing on vertebrate populations (Reynolds and Trost 1980). During the same period (1976 and 1977) I compared indices of small mammal abundance among 25 different areas on the INEL Site. My data do not corrobrate the conclusions of Reynolds and Trost regarding small mammals, but identify site specific variation in small mammal abundance.

\section{Study Areas}

The location and description of the INEL Site have been recently

The author is assistant professor, School of Forestry and Wildlife Management, Louisiana State University, Baton Rouge, Louisiana 70803.

This research was conducted under contract EY-76-S-071-1526 between the U.S. Department of Energy and Colorado State University.

Manuscript received May $28,1980$. described (Johnson 1979, Reynolds and Trost 1980). Twenty-five specific study transects were systematically established over the INEL Site; 12 were in the central area, which has not been grazed by livestock for more than 20 years, and 13 were in the livestock grazed periphery. Each transect was $700 \mathrm{~m}$ long (Fig. 1). Cattle and sheep grazed on separate allotments for several years prior to the study. Cattle generally grazed during winter and spring while sheep usually grazed during spring.

\section{Material and Methods}

Each end of transects was marked with an aluminum plate $(18 \times$ $18 \mathrm{~cm})$ attached to an iron reinforcement stake. Plates were stamped with the transect number(1-25), the date of establishment (July 1975) and the initials of investigators. Each transect number was suffixed with a letter to indicate whether the location was ungrazed (U), grazed (G), or near the common border for the areas (B). Five of the transects were near the border but each transect was totally in or out of the grazed area.

Common plants in the vicinity of each transect were visually ranked as to abundance in July 1976. In April 1977, 50 point locations were systematically chosen about each transect and the height of the shrub closest to each location was recorded. Twentyfive points were placed on each side of a transect at $25-\mathrm{m}$ intervals. Each point was $3 \mathrm{~m}$ from the transect. If no shrub occurred within 1 $\mathrm{m}$, then the height recorded was $0 \mathrm{~m}$. At each of the same 50 points a $0.1-\mathrm{m}^{2}$ wire loop was placed in the ground and the number of cottontail (Sylvilagus spp.) pellets was counted. Simultaneously, 


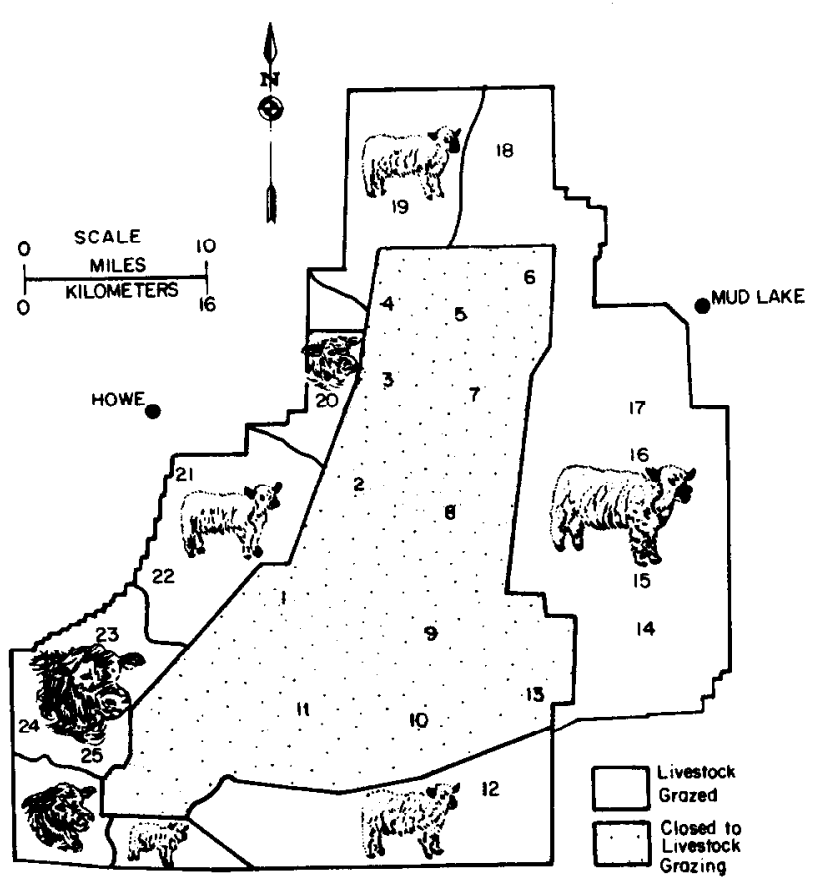

Fig. 1. A map of the INEL Site in central Idaho indicating the location of 25 transects distributed between livestock grazed and ungrazed areas.

the occurrence of each plant was recorded for every loop. Altogether, 1250 loops were sampled during the study.

Burrows of small mammals, northern pocket gopher (Thomomys talpoides) mounds, and tracks of ord kangaroo rats (Dipodomys ordii) were counted along a 6-m wide strip adjacent to either side of each transect. Burrows were placed into three categories: townsend groundsquirrel (Spermophilus townsendii), least chipmunk (Eutamias minimus), and mouse-sized. Only freshly used burrows were counted.

The topography of each area was ranked from $1-3$ as hilliness increased. Rockiness and sandiness of soils were classed as described by Chugg et al. (1968).

Rank order of plant abundance or frequency in loops was tested for significant associations by Friedman's tests (Conover 1971). Heights of shrubs were compared between areas and species by Student's $t$ tests (Snedecor and Cochran 1973).

\section{Results and Discussion}

The livestock grazed periphery contained the flatest topography while the central areas were more rolling and contained numerous basalt outcrops. Soils in the center of the INEL Site also contained more sand compared to the periphery, where rockiness was higher.

Rank order of plant abundance was significantly similar between areas $(\mathrm{T}=0.85 ; p<0.05)$. Dominant shrubs were basin big sagebrush (Artemisia tridentata) and douglas rabbitbrush (Chrysothamnus viscidiflorus). The upper shrub canopy was generally composed of sagebrush. Average heights of shrubs did not differ between areas $(p>0.10)$. Other shrubs that occurred were Utah juniper (Juniperus osteosperma), spiny hopsage (Grayia spinosa), saltbushes (Atriplex spp.), and other sagebrushes.

Relative frequency of occurrence for plants in loops was highly associated among areas $(\mathrm{T}=0.94: p<0.05)$ indicating that vegetational composition was highly similar among the transects regardless of whether grazing was by cattle or sheep, or whether there had been no grazing. Some differences in the understory composition were apparent. Most striking of these was the lack of wheatgrasses (Agropyron spp.) and pricklypear (Opuntia polyacantha), and the higher frequency of bottlebrush squirreltail (Sitanion hystrix) in grazed areas compared to ungrazed areas. However, there was proof whether this result was related to livestock grazing or to
Table 1. Small mammal abundance indices associated with perman transects on the Idaho National Engineering Laboratory Site in 19

\begin{tabular}{|c|c|c|c|c|c|c|}
\hline $\begin{array}{l}\text { Transect } \\
\text { identifier }\end{array}$ & $\begin{array}{l}\text { No. of } \\
\text { cottontail } \\
\text { rabbit } \\
\text { pellets } \\
\text { per } 0.1 \mathrm{~m}^{2} \\
(\mathrm{X} \pm \mathrm{SE})\end{array}$ & $\begin{array}{l}\text { No. of } \\
\text { ground- } \\
\text { squirrel } \\
\text { burrows }\end{array}$ & $\begin{array}{c}\text { No. of } \\
\text { least } \\
\text { chipmunk } \\
\text { burrows }\end{array}$ & $\begin{array}{c}\text { No. of } \\
\text { mouse } \\
\text { burrows }\end{array}$ & $\begin{array}{l}\text { No. of } \\
\text { ord } \\
\text { kangaroo } \\
\text { rat tracks }\end{array}$ & $\begin{array}{c}\text { No. ' } \\
\text { pock' } \\
\text { goph } \\
\text { moun }\end{array}$ \\
\hline 10 & $7.0 \pm 1.2$ & & 2 & & & \\
\hline $2 \mathrm{U}$ & $2.8 \pm 0.5$ & & & & & \\
\hline $3 \mathrm{U}$ & $1.9 \pm 0.3$ & & & 1 & & \\
\hline $4 U$ & $0.2 \pm 0.1$ & & & & & 6 \\
\hline $5 \mathrm{U}$ & $5.2 \pm 0.7$ & 13 & 11 & 5 & & 31 \\
\hline $7 \mathrm{U}$ & $5.8 \pm 1.1$ & 1 & & 7 & 38 & \\
\hline $8 \mathrm{U}$ & $8.1 \pm 1.7$ & 19 & & 4 & 9 & 5 \\
\hline $9 U$ & $11.6 \pm 1.5$ & 22 & & 9 & 6 & 11 \\
\hline $10 U$ & $3.8 \pm 1.1$ & & & 6 & & \\
\hline $11 \mathrm{U}$ & $3.1 \pm 0.4$ & & 17 & 9 & & 7 \\
\hline $6 \mathrm{~B}$ & $1.2 \pm 0.3$ & 15 & & 11 & & 3 \\
\hline 12B & $0.6 \pm 0.2$ & & 10 & 4 & & \\
\hline 13B & $1.4 \pm 0.5$ & & & 15 & & \\
\hline $20 \mathrm{~B}$ & $0.2 \pm 0.1$ & & 19 & 10 & & 5 \\
\hline 25B & $19.1 \pm 2.3$ & & 13 & 18 & & 3 \\
\hline $14 G$ & $0.9 \pm 0.2$ & 22 & 8 & 28 & & 1 \\
\hline $15 G$ & $0.5 \pm 0.1$ & & & 6 & & \\
\hline $16 \mathrm{G}$ & $0.7 \pm 0.2$ & & 17 & 12 & & \\
\hline $17 \mathrm{G}$ & $0.5 \pm 0.2$ & & & 11 & & \\
\hline $18 \mathrm{G}$ & $0.4 \pm 0.1$ & 89 & & & & 43 \\
\hline $19 \mathrm{G}$ & $0.1 \pm 0.1$ & 15 & 3 & 5 & & \\
\hline $21 \mathrm{G}$ & $0.3 \pm 0.1$ & 15 & 7 & 5 & & \\
\hline $22 G$ & $0.3 \pm 0.1$ & 8 & 3 & 4 & & \\
\hline $23 G$ & $<0.1$ & 36 & 5 & 14 & & \\
\hline $24 G$ & $2.1 \pm 0.5$ & & 15 & 6 & & 4 \\
\hline
\end{tabular}

other ecological relationships.

Cottontail pellets were most abundant in the central areas were ground squirrel burrows (Table 1). Ord kangaroo rat tra! were present only in the central areas and on three transects wh the soils were very sandy. Significant associations $(p<0.05) \mathrm{w}$ found between cottontail pellet abundance and hilly topograp Cottontails on the INEL Site were most abundant where bas outcrops provided cover (Johnson 1979). The association of , kangaroo rats with sandy soils is common knowledge and it was surprise to find a significant relationship of tracks vs. soil sandin $(p<0.05)$. Numbers of burrows were not correlated with to] graphy or soil characteristics and did not differ between grazed a ungrazed areas $(p>0.10)$.

There are strong associations of cottontail and ord kangaroo distributions with environmental characteristics that are unrela to livestock grazing. The ecological factors that control the dis butions of the other small mammals are less well known but the w variation in indices of abundance among transects in very simj vegetation and the lack of difference between grazed and ungra: areas suggests that livestock grazing does not limit the distribut of the important small mammals on the INEL Site. These resI do not support the conclusion of Reynolds and Trost (1980). addition, their data (p. 124) indicate a difference of only about 1 between total populations of small mammals on grazed ungrazed areas (187 total captures in ungrazed sagebrush vs. 15! grazed sagebrush). This difference is well within the normal ral of variation that should be expected among sites selected random.

Reynolds and Trost (1980) did obtain a large difference in sn mammal density between a natural area and one converted crested wheatgrass (Agropyron desertorun). Although, I did 1 study small mammal abundance on converted areas, it is fascin ing to note that Reynolds and Trost (1980) also obtained high sn mammal densities on one converted site while low densi occurred on only one site. This is hardly proof that livestc 
grazing or conversion significantly affected small mammal densities. This additional information is further testimony to the large variation in small mammal densities that can be expected regardless of land use. Experiments must be conducted before cause and effect relationships can be suggested from ecological data.

The wide variation reported here suggests that the abundance of small mammals is highly site specific. Reynolds and Trost (1980) and I chose areas with long histories of use or non-use by livestock for our studies. Neither they nor I studied the effects of livestock grazing. Studies should be conducted by placing livestock into grazed areas where populations of small mammals exist and have been studied. Dynamic changes in the populations should be monitored over time and compared with controls to determine whether livestock grazing significantly affects the welfare of wild animals. Since reproductive potential is high, small mammal populations respond very rapidly to ecological change. It is not necessary to conduct long term grazing studies to detect these responses. However, replication in the experiment is essential.

\section{Literature Cited}

Chugg, J.C., W. Jorgensen, and M.A. Fosberg. 1968. Special soil survey Butte County. Idaho Water Resources Board Report No. 5. 99 p.

Conover, W.J. 1971. Practical nonparametric statistics. John Wiley and Sons, New York. 462 p.

Johnson, M.K. 1979. Coyote food habits on the Idaho National Engineering Laboratory. J. Wildl. Manage. 43:952-956.

Reynolds, T.D., and C.H. Trost. 1980. The response of native vertebrate populations to crested wheatgrass planting and grazing by sheep. J. Range Manage. 33:122-125.

Snedecor, G.W., and W.G. Cochran. 1973. Statistical Methods. The lowa State Univ. Press. Ames. 593 p. 